\title{
MOVIMENTOS SOCIAIS E DIREITO: O SENTIDO DO ENFRENTAMENTO
}

\author{
SOCIAL MOVEMENTS AND LAW: THE MEANING OF CONFRONTATION
}

Gustavo Angelelli*

\begin{abstract}
Resumo:
O presente artigo tem a pretensão de descrever, com fundamento na teoria dos sistemas, tal como elaborada por Niklas Luhmann, um mecanismo específico desenvolvido pelos movimentos sociais, por meio do sentido, para realizar sua função de crítica à sociedade e enfrentamento aos sistemas funcionais, com foco no direito. A mobilização dos movimentos sociais pode ser descrita como condensação de consenso (interno), necessária à formação e unidade desses sistemas, com o propósito de afetar a estrutura do sistema funcional, propondo sua variação, de modo a gerar instabilidade no meio e reorientar a diferença entre atualizações e potencialidades no referido sistema - o que é feito com base na generalização de dissenso (externo).
\end{abstract}

Palavras-chave: Teoria dos sistemas. Sistema jurídico. Movimentos sociais. Sentido. Institucionalização. Consenso.

\begin{abstract}
:
This paper aims to describe, based on systems theory formulated by Niklas Luhmann, a specific mechanism developed by social movements, through meaning, to make their critical function against society and confrontation in face of the function systems, especially about law. The mobilization of social movements can be described as condensation of consensus (inner), necessary to the formation and unity of these systems, in order to affect the structure of the functional system, proposing its variation so that it creates instability in the medium and reorients the difference between update and potentialities into the mentioned system - what is made through the generalization of dissent (outer).
\end{abstract}

Keywords: Systems theory. Legal system. Social movements. Meaning. Institutionalization. Consensus.

1. Os movimentos sociais na sociedade moderna: a peleja contra os sistemas funcionais

Os movimentos sociais - especialmente o que se costuma chamar de "novos movimentos sociais" - são vistos, normalmente, como um fenômeno próprio da sociedade moderna - a depender, portanto, com relação a cada teoria, do que se entende por modernidade. ${ }^{1}$

Mestrando em Filosofia e Teoria Geral do Direito pela Faculdade de Direito da Universidade de São Paulo. Graduado em Direito pela Universidade Presbiteriana Mackenzie. Bolsista pela CAPES/PROEX.

1 Este artigo foi elaborado, originalmente, como trabalho de conclusão da disciplina "Movimentos sociais e acesso à justiça", ministrada pelo Professor Titular Celso Fernandes Campilongo, na Faculdade de Direito 
A teoria da sociedade desenvolvida por Niklas Luhmann compreende que a sociedade é caracterizada por sua forma de diferenciação, sendo que, na modernidade, essa forma consiste na diferenciação funcional.

Com base em uma teoria da evolução, o sociólogo alemão vislumbra diferentes formas de diferenciação historicamente verificadas na sociedade (segmentária, centro/periferia, estratificada), sendo que:

As sociedades estruturadas a partir da diferenciação funcional - sociedades modernas - diferenciam-se em subsistemas funcionais que são autopoiéticos e autoreferenciais, nos quais o que importa para a construção do sistema não é mais a posição de cada subsistema, mas sim a função que cada um desempenha na sociedade. ${ }^{2}$

Nesse diapasão, os movimentos sociais emergiriam como sistemas típicos da sociedade funcionalmente diferenciada, mas não por possuírem uma função exclusiva.

Luhmann entende que os movimentos sociais não são classificáveis como sistemas funcionais da sociedade, bem como não podem ser descritos simplesmente como organizações ou interações. Trata-se de um fenômeno que não pode ser compreendido sob essa tipologia. ${ }^{3}$

Como característica, "esos movimentos tratan de movilizar - por el solo hecho de estar siempre abiertos a nuevos adherentes - a la sociedad contra la sociedad". 4

Conforme ressalta Celso Fernandes Campilongo,

Os movimentos sociais fazem a crítica da sociedade. Logo, seus alvos são as lacunas, as inconsistências, as perversões, o mau funcionamento e os efeitos do próprio funcionamento dos sistemas de função. A sociedade que provoca a mobilização dos movimentos sociais é uma sociedade diferenciada funcionalmente. É nesse ambiente que os protestos são construídos. ${ }^{5}$

da USP, no primeiro semestre de 2013.

Sobre os teóricos dos novos movimentos sociais, em contraposição à teoria da mobilização de recursos e à teoria do processo político, cada qual possuindo sua própria concepção de modernidade, cf. ALONSO, Ângela. As teorias dos movimentos sociais: um balanço do debate. Lua Nova, n. 76, 2009, p. 49-86, especialmente p. 59 e ss.

2 VILLAS BÔAS FILHO, Orlando. Teoria dos sistemas e o direito brasileiro. São Paulo: Saraiva, 2009. p. 105.

3 Segundo Luhmann, "la tipología de sistemas desarrollada hasta ahora (sociedad, interacción, organización) no es suficiente para comprender otro fenómeno añadido", referindo-se aos movimentos sociais. LUHMANN, Niklas. La sociedad de la sociedad. Tradução de Javier Torres Nafarrete. México: Editorial Herder, 2006. p. 672.

4 Id. Ibid., loc. cit.

5 CAMPILONGO, Celso Fernandes. Interpretação do direito e movimentos sociais. Rio de Janeiro: Elsevier, 2012. p. 63. 
Nesses termos, os movimentos sociais estão necessariamente relacionados com a diferenciação funcional, ainda que eles próprios não sejam sistemas funcionais. ${ }^{6} \mathrm{Na}$ posição de críticos desta sociedade, emergem justamente por não o serem. ${ }^{7}$

Os movimentos sociais expressam o descontentamento de um grupo de pessoas, que se identificam em torno do protesto, vinculando este a um tema específico, semanticamente construído, para combater uma estrutura que impera na sociedade e gera exclusão. ${ }^{8}$

Como ressalta Celso F. Campilongo, “a reação típica dos protestos é a tradução de divergências". 9

Por meio de comunicação divergente, os movimentos sociais têm em vista perturbar a comunicação dos sistemas funcionais que já adquiriram redundância, para, com isso, provocar variação em razão do protesto. Referindo-se a possibilidades latentes no sistema contra o qual se protesta, ou então virtualizadas enquanto possibilidades apenas no horizonte de sentido dos movimentos sociais, isso pode ocorrer, inclusive, no sentido exatamente oposto ao vigente. Daí, a pretensão generalizada dos movimentos sociais de alterar a "ordem", de "lutar contra o sistema".

Nesses termos, a comunicação dos movimentos sociais pressupõe-se discordante. A luta é sempre por uma nova ordem, pela alteração das estruturas, do sentido regular das comunicações continuamente (re)atualizadas pelo sistema funcional.

E, uma vez que a maneira de perturbar o sistema funcional é a criação de instabilidade no interior do sistema-alvo (no presente caso, o sistema jurídico), especialmente, como veremos, pela condensação e generalização sobre a diferença consenso/dissenso, o meio para isso é a interferência na produção de sentido. Afinal, "produzir sentido significa produzir instabilidade". ${ }^{10}$

Os sistemas, no entanto, precisam manter uma relação estável com a própria instabilidade. "Os movimentos sociais produzem conflitos, geram instabilidade, abrem espaço para a variação das estruturas do sistema". ${ }^{11}$ Mas, questiona Celso F. Campilongo, “até onde vai a instabilidade necessária do sistema?". ${ }^{12}$ Nesse sentido, a prestação dos movimentos sociais aos sistemas funcionais, gerando conflitos e instigando a variação, é

\footnotetext{
6 "Si se quisiera, además, señalar la función de los movimientos de protesta podría decirse: se trata de reasentar en operaciones de la sociedad la negación de la sociedad”. LUHMANN, Niklas. op. cit., p. 685.

7 De acordo com Luhmann, os movimentos sociais não "son más que un sistema parcial de la sociedad, que sólo puede existir cuando él mismo no se apropia de la función del sistema funcional”. Id. Ibid., p. 637.

8 "Os movimentos sociais dos excluídos são portadores do protesto das pessoas". CAMPILONGO, Celso Fernandes. op. cit., p. 52.

9 Id. Ibid., p. 87.

10 Id. Ibid., p. 140.

11 Id. Ibid., p. 85.

12 Id. Ibid., p. 86.
} 
uma contribuição paradoxal: irrita o sistema de função, permitindo que este se reafirme constantemente na sociedade como sistema infungível e necessário; ao mesmo tempo, a irritação manifesta o potencial de provocar um colapso no sistema funcional, caso não seja capaz de reagir adequadamente à complexidade e regular a instabilidade de maneira estável.

2. Os mecanismos dos movimentos sociais para afetar o sentido dos sistemas funcionais

O sentido é o meio pelo qual sistemas psíquicos e sociais desenvolvem sua autopoiesis. ${ }^{13}$ Por isso, o conceito de sentido "se apresenta como um conceito central na teoria sistêmica, na medida em que possibilita a criação seletiva de todas as formas sociais e psíquicas". ${ }^{14}$

Segundo Luhmann, que parte da abordagem fenomenológica para analisar o sentido como conceito básico da sociologia, ${ }^{15}$ este fenômeno
aparece bajo la forma de un excedente de referencias a otras posibilidades de vivencia y acción (...). La totalidad de remisiones que surgen del objeto proveedor de sentido pone a la mano más posibilidades de facto que las que pueden realizarse en el siguiente movimiento. Por consiguiente, la forma de sentido obliga en el siguiente paso a la selección, debido a su estructura de remisión. ${ }^{16}$

Devido a essa conquista evolutiva denominada sentido, "forma indispensable e ineludible de complejidad y autorreferencia"17 tanto dos sistemas psíquicos quanto dos sistemas sociais, o sistema se vê obrigado a realizar seleções - e, quanto maior a complexidade, maior a exigência.

(...) el sentido es una representación de la complejidad.

El sentido no es una imagen o un modelo usado por los sistemas psíquicos o sociales, sino, simplemente, una

\footnotetext{
13 "Luhmann define o conceito de sentido como uma aquisição evolutiva que permite a criação seletiva dos sistemas psíquicos e sociais que, assim sendo, podem se tornar auto-referenciais, distinguindo-se do ambiente". VILLAS BÔAS FILHO, Orlando. op. cit., p. 7.

14 Id. Ibid., p. 95.

15 Cf. LUHMANN, Niklas. Sistemas sociales: lineamientos para una teoría general. Tradução de Silvia Pappe y Brunhilde Erker. Barcelona: Anthropos; México: Universidad Iberoamericana; Santafé de Bogotá: CEJA, Pontifícia Universidad Javeriana, 1998, p. 77ss. A respeito, ver também: Meaning as sociology's basic concept. In: Essays on Self-Reference. New York: Columbia University Press, 1990, p. 2179 , p. 24; e Complejidad y sentido. In: Complejidad y modernidad: de la unidad a la diferencia. Tradução de Josetxo Beriain e José María García Blanco. Madrid: Trotta, 1998, p. 25-30. p. 28.

16 LUHMANN, Niklas. Sistemas sociales. cit., p. 78.

17 Id. Ibid., p. 77.
} 
nueva y poderosa forma de afrontar la complejidad bajo la condición inevitable de una selectividad forzosa. ${ }^{18}$

Tanto movimentos sociais quanto o sistema jurídico, ambos sistemas sociais, têm o sentido como meio pelo qual podem atualizar suas operações, de forma que precisam lidar com a complexidade e desenvolver-se sobre essa base, realizando seleções entre as possibilidades que se apresentam no mundo, para, enfim, controlarem a própria instabilidade.

\section{Conforme explica Gabriel Cohn,}

O horizonte de possibilidades e as seleções no seu interior são associados, no esquema luhmanniano, à idéia de sentido (que, neste nível, dispensa o concurso direto do agente humano; este fica do lado de fora, oferecendo recursos para as operações significativas) e à idéia de diferença, que em Luhmann não pode ser dissociada da idéia de forma. ${ }^{19}$

Ora, o único meio de mobilização de qualquer sistema social é o sentido, pois é a partir dele que se estabelecem expectativas e que as operações elementares do sistema ganham forma. É com base no sentido, portanto, que os movimentos sociais poderão pretender afetar as estruturas do direito, que é um sistema autopoiético, operacionalmente fechado (ou seja, impassível de interferência operacional por outro sistema), para que este reconfigure o sentido das suas operações - o que, da perspectiva dos movimentos sociais, deve corresponder à seleção por eles proposta, de modo a culminar na congruência de sentido entre esses dois sistemas sociais que são, em realidade, operativamente irredutíveis um ao outro.

Procedendo a uma decomposição abstrata, Luhmann propõe que devemos distinguir dimensões de sentido, sendo delas a dimensão objetiva, a dimensão temporal e a dimensão social. ${ }^{20}$

Para exercerem sua função de mobilização crítica contra a sociedade, os movimentos sociais dispõem, na dimensão social, de um mecanismo que lhes permite conquistar a redundância necessária com relação à semântica proposta, o qual se centra na diferença entre consenso e dissenso.

A dimensão social fundamenta-se na distinção entre alter e ego e conta com um problema transversal, que faz possível ordenar as experiências desenvolvidas nessa dimensão. Esse problema é a oposição entre consenso e dissenso.

18 LUHMANN, Niklas. Complejidad y sentido. cit., p. 29.

19 COHN, Gabriel. As diferenças finas: de Simmel a Luhmann. Revista Brasileira de Ciências Sociais Associação Nacional de Pós-graduação em Pesquisa em Ciências Sociais, v. 13, n. 38, p. 53-62, out. 1998. p. 58.

20 Cf. LUHMANN, Niklas. Sistemas sociales, p. 90 ss. 
Sólo cuando el consenso se perfila como realidad o posibilidad es posible insertar el horizonte doble de lo social como una importante dimensión de orientación, y sólo en la medida en que esto suceda muy a menudo y con singular claridad en nexos de sentido específicos, surge en la evolución social una semántica particular de lo social que, a su vez, como teoría de esta diferencia, es capaz de consenso o de disenso. ${ }^{21}$

Para que o Direito possa exercer sua função específica na sociedade moderna, isto é, a estabilização contrafática de expectativas normativas, por meio da generalização congruente nas três dimensões de sentido, Luhmann afirma que na "dimensão social essas estruturas de expectativas podem ser institucionalizadas, ou seja apoiadas sobre o consenso esperado a partir de terceiros". ${ }^{22}$

Orlando Villas Bôas Filho explica que a institucionalização "remete ao consenso pressuposto das expectativas institucionalizadas, de modo que estas pressuporiam o concurso de terceiros que supostamente estariam dispostos a sustentá-las contra as condutas que as frustram". ${ }^{23}$

Ademais, Luhmann ressalta, contrariamente a concepções que vão da sociologia clássica a Habermas, passando por Parsons, que não é adequada a abordagem do problema do consenso como algo desejável ou como uma variável empírica. Segundo ele,

O problema não pode consistir em ampliar-se o consenso consideravelmente. Isso absorveria o potencial de atenção disponível para outros temas, esgotando-o rapidamente. A institucionalização de expectativas sobre expectativas só poderá estar voltada para o melhor aproveitamento de um mínimo em experiências simultâneas e sinônimas, distribuindo-as igualmente entre os significados e os momentos socialmente relevantes, tornando o consenso expectável e ativável caso necessário, mas principalmente expandindo as predisposições ao consenso, de tal forma que o "consenso social geral" só precise ser coberto pela experiência atual de algumas pessoas, em alguns sentidos e em alguns momentos. Dessa forma, a função das instituições reside menos na criação e mais na economia do consenso, que é atingida, principalmente, na medida em que o consenso é antecipado na expectativa sobre expectativas,

\footnotetext{
$21 \quad$ Id. Ibid., p. 95.

22 Sociologia do direito. Tradução de Gustavo Bayer. Rio de Janeiro: Edições Tempo Brasileiro, 1983. v. 1, p. 109 .

23 VILLAS BÔAS FILHO, Orlando. op. cit., p. 135.
} 
ou seja, como pressuposto, não mais precisando, em geral, ser concretamente expresso. ${ }^{24}$

Estando o consenso apenas pressuposto para a reprodução do sistema jurídico, os movimentos sociais buscam tematizá-lo e mostrar que, concretamente, ele não se sustenta. Isso é feito por meio de temas indicadores dos paradoxos do direito, como a injustiça ou o desrespeito a direitos, e tem como finalidade pressionar o direito por mudanças, por meio do questionamento de um de seus pressupostos.

Nesse sentido, podemos afirmar que os movimentos sociais são sistemas que condensam consenso para generalizar dissenso.

Isso decorre, inclusive, da constituição do movimento social com base na forma protesto, isto é, da distinção entre aquele que protesta e aqueles a quem se dirige o protesto. Estando sempre aberto a novos aderentes, "los movimientos de protesta tienen que reclutar a sus seguidores e impresionar a los adversarios", ${ }^{25}$ ou seja, desestabilizar as expectativas do sistema jurídico, por meio da formação de consenso sobre a necessidade de se colocar em xeque o consenso pressuposto por esse sistema.

Conforme ressalta Luhmann, a respeito da sociedade:

La sociedad entonces se describe a sí misma como se pudiera contar con un consenso totalmente asegurado a través de principios, códigos y programas - como si hubiera una opinión pública. ${ }^{26}$

Em resposta, os movimentos sociais têm em vista promover a ressonância das expectativas divergentes, para propagar o fato de que a sociedade se descreve mal e que se deve formar consenso sobre isso.

Com a generalização do dissenso a partir da condensação de consenso como pano de fundo, tematiza-se um sentido de comunicação, apresentando-o como inconsistente, precário, obsoleto (na semântica dos movimentos sociais: injusto, desigual, explorador, preconceituoso, corrupto), oferecendo-se normalmente em troca, de forma simultânea, uma alternativa, ainda que pouco concreta, para que as comunicações seguintes tenham seu sentido alterado, reconhecendo que a descrição proposta pelos movimentos sociais é mais coerente e merece adesão.

Com base nessa estratégia fundamental, os movimentos sociais promovem uma condensação das comunicações que, sobre o mesmo alicerce semântico, indicam a necessidade de mudança, identificada como variação nos sistemas confrontados.

\footnotetext{
24 LUHMANN, Niklas. op. cit., p. 80.

25 LUHMANN, Niklas. La sociedad de la sociedad. cit., p. 681.

26 Id. Ibid., p. 156.
} 
Por isso, muitas vezes, movimentos sociais diversos (como o feminista e o ambientalista) conseguem unir-se em torno de uma semântica provisoriamente mais abstrata do que a que cada um deles usualmente utiliza, de modo a abarcar os diversos movimentos sociais, momentaneamente, num mesmo contexto, em que a "ordem" combatida se lhes apresenta em comum. ${ }^{27}$

Assim, uma vez realizada a condensação (seja para formar um movimento social, seja para unir diversos movimentos sociais), cria-se um núcleo comunicativo, que dá unidade ao movimento social, cujo sentido este pretende confirmar, difundir e generalizar, para afetar as atualizações de sentido estabelecidas pela comunicação dominante (isto é, a comunicação produzida pelo sistema funcional).

Desse modo, o objetivo não é apenas condensar consenso, mas condensá-lo para generalizar o dissenso com relação ao sentido de comunicação vigente no sistema funcional. $\mathrm{O}$ objetivo é desconstruir a semântica para alterar a estrutura.

\section{Sistema jurídico e movimentos sociais deparados}

Devido à diferenciação funcional, a comunicação cujo sentido se combate, construída e generalizada internamente por cada sistema de função, pouco se deixa afetar por variações radicais como as que propõem os movimentos sociais (principalmente porque decorrentes de irritações construídas como problemas a partir de variações do ambiente, não como informação específica do próprio sistema).

Os sistemas funcionais têm meios de reduzir a complexidade e manter o sentido em que operam. Suas comunicações gravitam em torno de códigos rígidos ${ }^{28}$ e têm nos meios de comunicação simbolicamente generalizados ${ }^{29}$ uma garantia de estabilidade.

Os meios de comunicação simbolicamente generalizados existem justamente para transformar a improvável aceitação da comunicação em um advento provável. Isso é

27 Especialmente com base nas formas da igualdade interna e do equilíbrio externo, que teriam logrado particular proeminência na criação de temas, cf. LUHMANN, Niklas. La sociedad de la sociedad. cit., p. 680.

28 "Los códigos (...) son distinciones con las que un sistema observa las propias operaciones y define su unidad: permiten reconocer cuáles operaciones contribuyen a su reproducción y cuáles no". Nesse sentido, "cada una de las operaciones orientada al código contribuye a fijar los confines del sistema en las relaciones de lo que le es externo y a especificar uniones internas, de modo que recursivamente se crea un retículo de comunicaciones conexas que desarrolla una forma de independencia del resto de la sociedad". CORSI, Giancarlo; ESPOSITO, Elena; BARALDI, Claudio. GLU: Glossario sobre la teoría social de Niklas Luhmann. Tradução de Miguel Romero Pérez e Carlos Villalobos. México: Universidad Iberoamericana, 1996. p. 42.

29 "Los medios de comunicación generalizados simbólicamente (...) son estructuras particulares que aseguran probabilidades de éxito a la comunicación, porque transforman en probable el hecho improbable de que una selección de Alter sea acepta por Ego. Tales medios son el poder (o poder/derecho), la verdad científica, el dinero (o propiedad/dinero), el amor, el arte, los valores”. CORSI, Giancarlo; et al., p. 106. 
feito, em resumo, pelo estabelecimento de um nexo entre condicionamento e motivação, permitindo que se elevem as expectativas de aceitação daquilo que é comunicado. ${ }^{30}$

Assim, não obstante o esforço engendrado pelos movimentos sociais para forçar novas seleções, alterando o sentido da comunicação dos sistemas funcionais, para além da impossibilidade de interferência direta do sistema no seu ambiente - ainda que se trate de sistemas transversais, sem código e função exclusiva -, afigura-se improvável que os sistemas funcionais promovam a alteração do sentido de suas comunicações conforme expectativas que não o estruturam, uma vez que possuem o referido mecanismo para assegurar a aceitação de suas comunicações. Ademais, ainda que o sentido fosse alterado, a improbabilidade é de grau ainda mais elevado com relação à seleção específica proposta pelos movimentos sociais (isto, quanto há alguma, pois podem pautar-se em uma expectativa negativa: “isto não", simplesmente, sem se especificar a possibilidade que deve ser atualizada).

De fato, se os movimentos sociais buscam a variação no sentido da comunicação, por meio de novas seleções, eles estão propondo desvios na comunicação corrente. E esses desvios são muito mais improváveis do que a continuidade da rede de comunicações estabelecida em um sistema funcional com base na estrutura de expectativas por ele construída e com a segurança de aceitação propiciada pelos meios de comunicação simbolicamente generalizados.

Por outro lado, pesa aos movimentos sociais a dependência de temas e de manifestações como meios para expor a questionamento o consenso fictício que dá suporte à institucionalização das expectativas comportamentais pelo sistema jurídico.

Com efeito, segundo Luhmann,

as instituições podem tornar-se amplamente independentes da distribuição fática das experiências reais com respeito a temas e momentos, e também das entradas e saídas de seus participantes, passando então a moldar elas mesmas a estrutura de expectativas desses processos. Ao nível das expectativas sobre expectativas, elas atingem um grau tão característico de sedimentação, ao ponto de não mais tolerarem um recurso à realidade concreta das opiniões e do comportamento. ${ }^{31}$

Assim, no interior do sistema jurídico, comunicações desviantes, faticamente engendradas, não são suficientes para colocar em questão a estabilidade das instituições, que se mantêm independentes dos temas e momentos que revestem a

$30 \quad$ Cf. LUHMANN, Niklas. op. cit., p. 156.

31 LUHMANN, Niklas. Sociologia do direito. cit., v. 1, p. 84-85. 
experiência. O mínimo consenso pressuposto permanece inabalado diante de divergências concretas e situacionais.

Ainda sobre as instituições, Luhmann ressalta:

A certeza de suas expectativas se baseia na assimilação de hipóteses improvisadas que não foram oportunamente refutadas, no descobrimento de suas implicações e de outras possibilidades, no manter latente a maior parte dos desvios e todas as comunicações que sinalizem expectativas divergentes e que possam dar-lhes ressonância social mas principalmente na dilatação das chances fáticas de consenso. ${ }^{32}$

Portanto, a tarefa de enfrentamento dos sistemas funcionais assumida pelos movimentos sociais, os críticos da sociedade funcionalmente diferenciada, esbarra em um paradoxo: enquanto pretendem abalar o consenso que as instituições jurídicas pressupõem, apontando possibilidades divergentes a serem atualizadas pelo sistema jurídico, a fim de produzir a comunicação desviante, é justamente na manutenção em estado de latência dessas possibilidades que as instituições encontram a certeza de suas expectativas.

As instituições - como os procedimentos, por exemplo - têm como pressuposto o consenso de terceiros sobre a estrutura de expectativas. Os movimentos sociais mostram que não há consenso de fato. Mas os procedimentos, ao chamarem a atenção para si e para as expectativas que mantêm em torno do conflito que envolvem, lembram que isso deve ser esquecido.

Em resumo, pode-se afirmar que, por meio da tematização de uma questão social marcada pela insígnia da insatisfação, os movimentos sociais miram a dimensão social dos sistemas funcionais, a fim de descaracterizar, no caso do direito, a institucionalização jurídica, por meio do rompimento do consenso.

Como o consenso, no direito moderno, tal como descrito pela teoria dos sistemas luhmanniana, está construído como consenso mínimo, temas faticamente indicados pelos movimentos sociais não podem, concretamente, afetá-lo.

Afinal, a institucionalização

antecipa ficcionalmente o consenso, de modo a fazer com que ele passe a ser pressuposto e não precise mais ser concretamente expresso. Sua função é menos a ampliação do consenso que a simples distribuição de riscos, que faz com que as expectativas e condutas contrárias à instituição tenham contra si o peso de uma auto-evidência presumida. ${ }^{33}$

$32 \quad$ Id. Ibid., p. 85.

33 VILLAS BÔAS FILHO, Orlando. op. cit., p. 135-136. 
Assim, malgrado o protesto aponte problemas no sistema jurídico, com base em temas como justiça, meio ambiente ou sexualidade (a título de exemplo), em torno dos quais os movimentos sociais gravitam, a única maneira de romper o consenso institucionalizado em um sistema funcional é gerando desconfiança nas instituições, como o procedimento.

O desdobramento temporal do procedimento, por exemplo, deve ser impedido, para que este perca o controle sobre as expectativas que envolvem o conflito.

Por isso, a luta por justiça, para realizar o fim dos movimentos sociais, sob o esquema consenso/dissenso, precisa atacar o procedimento: gerar desconfiança no Poder Judiciário, propor planos para reforma no aparato estatal, para reforma agrária (o que colocaria em questão o modelo de propriedade e contrato), dentre outros focos de protesto.

Por outro lado, é possível que os movimentos sociais, em vez de afetarem as instituições, promovendo o rompimento do consenso, utilizem-nas como instrumentos válidos e necessários para seu pleito.

Assim, os movimentos que tematizam o meio ambiente ou a sexualidade precisariam defender o reconhecimento de suas reivindicações por meio da redação de leis que assegurem a proteção ambiental ou a igualdade, respectivamente, ou pela mudança de jurisprudência, valendo-se de processos judiciais.

\section{A reação do direito ao protesto}

O Direito, enfrentado pelos movimentos sociais, não permanece indiferente. Seu ambiente produz variação. Irritado, o direito reage como pode: por meio de suas operações, pautadas na estrutura de expectativas e na memória ${ }^{34}$ que constrói por meio do sentido.

Como um dos principais mecanismos do direito, a interpretação jurídica gera sentido. "Alimenta-se de redundância e é fermento de variações no sentido do direito". 35

A atuação dos movimentos sociais se dá exatamente enquanto negação do sentido já produzido (é um "não" ao "sim" da sociedade - o qual, simultaneamente,

\footnotetext{
34 "Por meio da função da memória, o sistema é presente a si mesmo. Isto permite ao sistema isolar, na rede de contínuos re-envios simultâneos de modificações de estados, aquela modificação de estado que pode se sintetizada como relevante para um novo comportamento e, conseqüentemente, neste momento, como estado momentaneamente capaz de conexão". DE GIORGI, Raffaele. Direito, tempo e memória. Tradução de Guilherme Leite Gonçalves. São Paulo: Quartier Latin, 2006. p. 59. Assim, "através de sua memória, o sistema se estabiliza permanentemente e torna-se continuamente imprevisível para si próprio". Id. Ibid., p. 60.

35 CAMPILONGO, Celso Fernandes. op. cit., p. 139.
} 
redundara em "não" àqueles que mobilizam o movimento social) e proposta de variação, de transmutação do "sim" em "não" e do respectivo "não" em "sim" - isto é, variação que resulte na inclusão dos excluídos que protestam.

O enfoque, na dimensão social, como vimos, reside no esquema consenso/ dissenso. O direito depende da institucionalização, que pressupõe o consenso, para funcionar. O movimento social se forma com a condensação de consenso em torno do tema da insatisfação, expondo a defasagem e a precariedade do sistema jurídico, o que é feito com respaldo na diferença interno/externo. Sendo o lado interno identificado como essa unidade consensual do movimento social, o lado externo é indicado justamente como o sistema defasado, contra o qual se protesta, em busca de corrigi-lo ou destruí-lo. A reconstrução ou desconstrução do sistema jurídico, portanto, deve-se dar com base na geração de desconfiança, abalando a estrutura institucionalizada e, consequentemente, o consenso sobre os quais o direito produz a generalização de expectativas.

Tendo em vista que a função do direito é a estabilização das expectativas normativas, por meio da generalização congruente destas, e sendo a interpretação jurídica modo de observação da sociedade e de construção de sentido, é ela tanto um alvo privilegiado dos movimentos sociais, pois guarda a possibilidade de realizar as alterações, como um mecanismo de proteção do direito, uma vez que pode garantir a manutenção das expectativas. Afinal, a interpretação jurídica "reduz complexidade, produz seleções, reenvia o sentido do direito para os demais sentidos do direito e da sociedade" ${ }^{36}$

Nessas condições, os tribunais, que compõem o centro do sistema jurídico, encarregados de produzir interpretação e validá-la por meio de decisão, aparecem em posição de destaque.

De fato, "abre-se no plano judicial enorme potencial para provocação de variabilidade no próprio sistema jurídico". ${ }^{37}$ Ainda que a variação proposta em forma de protesto não seja adotada no sentido indicado, que o tribunal responda a ela com "não", abre-se um novo horizonte de expectativas que permite (e mesmo exige) que o direito lide com um crescente contingente de possibilidades.

A variação, ocorrida no ambiente, comunicada internamente como problema e transformada em informação, faz com que seja incrementada variabilidade também no sistema jurídico, culminando na evolução do direito.

Isso, frise-se, independentemente da seleção adotada nas comunicações seguintes, seja correspondente às expectativas dos movimentos sociais, seja frustrando-as.

A capacidade de efetivamente alterar o sentido, a propensão a isso (isto é, a sensibilidade do Direito aos movimentos sociais), a efetivação das mudanças e a

\footnotetext{
$36 \quad$ Id. Ibid., p. 140.
}

37 Id. Ibid., p. 87. 
configuração histórica do sistema jurídico frente às inquietações sociais de que são portadores os movimentos sociais são fatores que influenciarão no tipo de protesto: se "contra", "pelo" ou "após" o direito, se movimento de integração ou movimento de desintegração. ${ }^{38}$

Assim, por exemplo, podem se formar, para enfrentar o direito, estes dois tipos de movimentos sociais: movimentos de integração, que surgem com a pretensão de romper a autonomia do sistema de função, e movimentos de desintegração, que buscam satisfação por meio de variações específicas que mantenham a autonomia e infungibilidade do sistema contra o qual protestam.

Nesse sentido, malgrado seja maior a exigência geral dos movimentos de integração, pois visam a uma ruptura da unidade do sistema funcional, improvável porque se dirige contra a própria forma de diferenciação da sociedade, a mera ruptura basta para a conquista de sua finalidade.

Os movimentos de desintegração, por outro lado, que manifestam exigência menos colossal, mais provável, uma vez que se mantém a forma da sociedade, podem apresentar exigência excessiva em termos de especificação, de sorte que é altamente improvável que o exato sentido de seleção proposto seja alcançado. Não-obstante o Direito produza variação, o movimento de desintegração dificilmente encontrará satisfação.

De qualquer maneira, em toda situação, "el sistema jurídico debe garantizar una consistencia suficiente de sus decisiones; es decir, debe desempeñarse, en este caso, como unidad". 39

Os movimentos sociais mobilizam-se, frente ao sistema jurídico, para afetar essa consistência, colocando em questão (e em risco) a própria unidade do sistema. Isso ocorre pela exposição dos paradoxos constitutivos do direito, num movimento contraposto à pretensa garantia de consistência operada pelo sistema jurídico em nome de sua unidade e autonomia. Nesse sentido, Celso F. Campilongo observa que os "os movimentos sociais provocam a realidade do direito. Ajudam a revelar, esconder e desdobrar os paradoxos constitutivos do direito". ${ }^{40}$

Essa é a maneira pela qual os movimentos sociais produzem questionamento sobre o sistema jurídico - seja parcialmente, também maquilando, por diferenças escolhidas, alguns paradoxos, mas justamente para colocar outros em evidência e corrigir as "injustiças" (desigualdades e desequilíbrios), seja como um todo, tematizando o caráter

\footnotetext{
38 Sobre as maneiras pelas quais se pode dar "a aposta dos movimentos sociais no direito", cf. Id. Ibid., p. 34 ss. Sobre a diferença entre movimentos de integração (ou de protesto) e movimentos de desintegração, cf. Id. Ibid., p. 63 ss., p. 103 ss.

39 LUHMANN, Niklas. El derecho de la sociedad. Tradução de Javier Torres Nafarrete, com a colaboração de Brunhilde Erker, Silvia Pappe e Luis Felipe Segura. 2. ed. em espanhol. México: Herder, 2005. p. 134.

40 CAMPILONGO, Celso Fernandes. op. cit., p. 164.
} 
paradoxal do sistema jurídico em sua unidade, para promover a ruptura - quiçá, propondo uma "revolução" na Justiça.

Assim, exposto, o direito pode ver-se obrigado a promover mudanças imprevistas, que lhe permitam lidar com a contingência e manter regulada sua instabilidade - o que, visto de outro ângulo, pode consistir na conquista do objetivo do protesto pelos movimentos sociais; afinal, estes terão logrado incutir a crise que manifestam (e de que são manifestação) no sistema de função enfrentado.

No entanto, é necessário deixar claro que os movimentos sociais, por si, não podem alterar outros sistemas, que formam o seu ambiente, em virtude do fechamento operacional que assegura a autopoiesis sistêmica.

Os novos movimentos sociais perseguem o objetivo de mudar o direito. Em casos extremos, não só o direito: mudar a sociedade. No interior do sistema jurídico, a pretensão de mudança (...) assume diferentes orientações: (i) simplesmente ridicularizar e protestar contra o direito; (ii) apostar no direito unicamente em razão do espaço que ele mesmo oferece para suas modificações; (iii) ver no direito um sistema que pode estabilizar expectativas e promover reestruturação de expectativas. ${ }^{41}$

Os movimentos sociais, portanto, têm por objetivo mudar o sistema funcional - no caso, o direito. Procuram afetar as dimensões de sentido do sistema jurídico, para que este altere as futuras seleções, de modo a aceitar a variação no sentido de inclusão proposto pelos movimentos sociais.

Contudo, qual é o resultado disso, não diz respeito ao movimento social senão enquanto ambiente, uma vez que é incapaz de interferir operativamente na autopoiesis do sistema de função.

Apenas por meio de abertura cognitiva, com o reconhecimento de que novas seleções são promovidas no seu próprio ambiente - mais precisamente, no sistema funcional -, o movimento social também poderá reestruturar o horizonte de suas expectativas.

Os critérios devem ser buscados e construídos no direito e pelo próprio direito. Isso pode implicar diversos tipos de resposta aos movimentos sociais e aos grupos contrapostos. Negação ou aceitação das mudanças pleiteadas no direito, ou seja, redundância ou variação do sistema, é o que está em jogo. A reorientação de expectativas pode ocorrer, mas por conta de operações internas - dentre elas a interpretação do próprio sistema". ${ }^{42}$

$41 \quad$ Id. Ibid., p. 158.

42 Id. Ibid., loc. cit. 
Afinal, "nada penetra no sistema sem passar pelas suas operações próprias: o que está fora só se torna relevante, vale dizer, significativo mediante as operações seletivas do próprio sistema auto-referido". ${ }^{43}$

\section{Conclusão. O fim do protesto}

Por derradeiro, cabe a pergunta sobre qual é o fim desse direcionamento dos movimentos sociais como sistemas que condensam consenso para generalizar dissenso. Tenderiam, uma vez conquistado o dissenso, à promoção de um novo consenso no sistema funcional?

Ainda que essa seja a finalidade que subjaz à atuação dos movimentos sociais, em termos sistêmicos, descrita dessa maneira, sua consecução é irrealizável.

Os movimentos sociais, enquanto sistemas que concentram insatisfação, isto é, que tematizam comunicação desviante, têm a tendência de buscar a atualização do desvio na comunicação, alterando as expectativas que estruturam a rede comunicativa do sistema funcional.

Para tanto, condensam consenso para generalizar dissenso.

Uma vez conquistado o dissenso, com base no consenso previamente condensado, a nova condensação e generalização do consenso será fruto da autopoiesis do próprio sistema funcional que sofreu a variação. Isto é, estará integrada ao encadeamento operativo de um sistema parcial da sociedade funcionalmente diferenciada, tratada com base no código correspondente à função desse mesmo sistema e construída conforme a estrutura de expectativas deste. ${ }^{44}$

Um observador pode, a partir de uma atribuição causal, narrar que a estrutura de expectativas do direito foi afetada em razão do protesto promovido pelo movimento social.

Mas o consenso formado no direito não dirá respeito, então, ao movimento social senão enquanto ambiente, pois se terá construído como pressuposto das expectativas do próprio sistema jurídico.

São Paulo, junho de 2013.

43 COHN, Gabriel. op. cit., p. 59.

44 Segundo Luhmann, "los sistemas funcionales en gran medida asimilan y absorben los temas de la protesta. (...) Los movimientos de protesta viven de la tensión (y por ella también perecen) entre tema y protesta. Éxito y falta de éxito son igual de fatales. La transformación exitosa del tema acontece fuera del movimiento y, en el mejor de los casos, se le atribuye como "mérito histórico'. La falta de éxito desanima a los participantes". LUHMANN, Niklas. La sociedad de la sociedad. cit., p. 680. 


\section{Referências}

ALONSO, Ângela. As teorias dos movimentos sociais: um balanço do debate. Lua Nova, n. 76, p. 49-86, 2009.

CAMPILONGO, Celso Fernandes. Interpretação do direito e movimentos sociais. Rio de Janeiro: Elsevier, 2012.

COHN, Gabriel. As diferenças finas: de Simmel a Luhmann. Revista Brasileira de Ciências Sociais - Associação Nacional de Pós-graduação em Pesquisa em Ciências Sociais, v. 13, n. 38, p. 53-62, out. 1998.

CORSI, Giancarlo; ESPOSITO, Elena; BARALDI, Claudio. GLU: Glossario sobre la teoría social de Niklas Luhmann. Tradução de Miguel Romero Pérez e Carlos Villalobos. México: Universidad Iberoamericana, 1996.

DE GIORGI, Raffaele. Direito, tempo e memória. Tradução de Guilherme Leite Gonçalves. São Paulo: Quartier Latin, 2006.

LUHMANN, Niklas. Complejidad y sentido. In: . Complejidad y modernidad: de la unidad a la diferencia. Tradução de Josetxo Beriain e José María García Blanco. Madrid: Trotta, 1998. p. 25-30.

. El derecho de la sociedad. Tradução de Javier Torres Nafarrete, com a colaboração de Brunhilde Erker, Silvia Pappe e Luis Felipe Segura. 2. ed. em espanhol. México: Herder, 2005.

. La sociedad de la sociedad. Tradução de Javier Torres Nafarrete. México: Herder, 2006.

. Meaning as sociology's basic concept. In: . Essays on Self-Reference. New York:

Columbia University Press, 1990, p. 21-79.

. Sistemas sociales: lineamientos para una teoría general. Tradução de Silvia Pappe y Brunhilde Erker. Barcelona: Anthropos; México: Universidad Iberoamericana; Santafé de Bogotá: CEJA, Pontifícia Universidad Javeriana, 1998.

. Sociologia do direito. Tradução de Gustavo Bayer. Rio de Janeiro: Edições Tempo Brasileiro, 1983. v. 1.

VILLAS BÔAS FILHO, Orlando. Teoria dos sistemas e o direito brasileiro. São Paulo: Saraiva, 2009. 